\title{
The Social Dimension of Legal Uncertainty
}

Reconciling Law and Science in the Formative Years of Pragmatism

Frederic Kellogg

\section{(2) OpenEdition \\ Journals}

Electronic version

URL: http://journals.openedition.org/ejpap/543

DOI: $10.4000 /$ ejpap.543

ISSN: 2036-4091

Publisher

Associazione Pragma

\section{Electronic reference}

Frederic Kellogg, "The Social Dimension of Legal Uncertainty », European Journal of Pragmatism and American Philosophy [Online], V-2 | 2013, Online since 24 December 2013, connection on 22 April 2019. URL : http://journals.openedition.org/ejpap/543 ; DOI : 10.4000/ejpap.543

This text was automatically generated on 22 April 2019

\section{(c) $(1)$}

Author retains copyright and grants the European Journal of Pragmatism and American Philosophy right of first publication with the work simultaneously licensed under a Creative Commons AttributionNonCommercial-NoDerivatives 4.0 International License. 


\section{The Social Dimension of Legal Uncertainty}

Reconciling Law and Science in the Formative Years of Pragmatism

Frederic Kellogg

Almost everyone knows Lord Mansfield's advice to
a man of practical good sense, who, being
appointed governor of a colony, has to preside in
its courts of justice, without previous judicial
practice or legal education. The advice was to give
his decision boldly, for it would probably be right,
but never to venture on assigning reasons, for they
would almost infallibly be wrong.
John Stuart Mill, A System of Logic, 1843

1 The above passage, from J. S. Mill's A System of Logic, is part of Mill's contribution in the 19th century to a debate (with Bishop Whately) over whether the logical syllogism "is, or is not, a process of inference; a progress from the known to the unknown: a means of coming to a knowledge of something which we did not know before." Mill employs a familiar story about Lord Mansfield to support his contention that reasoning is inaccurately depicted by the classic syllogistic form. Rather than being informed by generals, "[a]ll inference is from particulars to particulars." The formal syllogism, says Mill, adds nothing to logical thought: "Not one iota is added to the proof by interpolating a general proposition" (Mill, 1862: 232). Mill continues:

Since the individual cases are all the evidence we can possess, evidence which no logical form into which we choose to throw it can make greater than it is; and since that evidence is either sufficient in itself, or, if insufficient for the one purpose, can not be sufficient for the other; I am unable to see why we should be forbidden to take the shortest cut from these sufficient premises to the conclusion, and constrained to travel the "high priori road," by the arbitrary fiat of logicians. (Mill, 1862: 232-3)

2 The illustratory example chosen here is drawn from law - specifically from judicial practice. This passage introduces my subject, the social dimension of thought: in 
particular, with regard to the disparate fields of law and science, as conceived in the formative years of pragmatism. The Lord Mansfield story suggests the difficulty of applying syllogistic inference to unique disputes for the individual observer. The young Oliver Wendell Holmes Jr, immersed in the records of actual cases, suggested an explanation. The syllogism models how the mind operates to justify knowledge of undisputedly similar facts; but judges are engaged in resolving disputed facts.

They are also part of a community of inquiry, consisting of other judges, lawyers, and indeed the parties affected by the disputes in question. Influenced by peers in Cambridge, perhaps also by his recent experience in the Civil War, Holmes looked to the effects of society on thought, and the question of how a community resolves doubt and reaches conclusions.

4 In the period before the American Civil War, Mill was engaged in another celebrated debate, with William Whewell, over the nature and grounds of scientific discovery. The young post-war intellectuals in Cambridge, Massachusetts (the founders of pragmatism, gathering in the so-called "Metaphysical Club") were keenly aware of it. Some were reading its main sources, including Mill's Logic and Whewell's Philosophy of the Inductive Sciences, even as they designed their own radical naturalist approach to knowledge that would later be called pragmatism.

5 The passage from Mill connects the pragmatist interest in the logic of science with the logic of law, in a common vision of social inquiry. Max Fisch noted in 1942 (Fish, 1942) that half the membership of the early Metaphysical Club consisted of scientists and half lawyers, and that the two perspectives informed each other. Some evidence of this may be found in the diary of reading kept by the young Oliver Wendell Holmes, Jr., recently returned from the battles of the Civil War. Even while immersing himself in legal treatises and a daunting revision of the encyclopedic Kent's Commentaries on American Law, Holmes was discussing philosophy with William James and Chauncey Wright, and, after attending a lecture on Mill by Charles Peirce, slogging through Mill's lengthy and dense System of Logic in 1866.

6 Holmes's principal work, The Common Law (1881), notably begins with the famous passage, "The life of the law has not been logic: it has been experience. The felt necessities of the time, the prevalent moral and political theories, intuitions of public policy, avowed or unconscious, even the prejudices which judges share with their fellow-men, have had a good deal more to do than the syllogism in determining the rules by which men should be governed"(1881: 1). This community-conscious comment warrants a look at the early period of Holmes's writing to explore his thought about the syllogism.

7 In 1870 we find Holmes, in a formative essay on law, repeating Mill's story of Lord Mansfield's comment, in a text which addresses the relationship of particulars and generals in the law:

It is the merit of the common law that it decides the case first and determines the principle afterwards... In cases of first impression Lord Mansfield's often-quoted advice to the business man who was suddenly appointed judge, that he should state his conclusions and not give his reasons, as his judgment would probably be right and the reasons certainly wrong, is not without its application to more educated courts. It is only after a series of determinations on the same subject-matter, that it becomes necessary to "reconcile the cases," as it is called, that is, by a true induction to state the principle which has until then been obscurely felt. And this statement is often modified more than once by new decisions before the abstracted general rule takes its final shape. A well settled legal doctrine embodies the work of 
many minds, and has been tested in form as well as substance by trained critics whose practical interest it is to resist it at every step. (Holmes, 1870:1) "reasoning from particulars to particulars." But the relation of particulars to generals is different. Holmes adds an element of the emergence of generals from particulars, entirely missing from Mill's account. Whereas Mill had set forth his argument as a rejection of classical logical form, Holmes goes on to address how, in an historical simulation, general rules are attained in a progression from particular judgments to consensually negotiated generals. It would occupy a key place in his thought and career, a vision that he would much later characterize as showing the "morphology of human ideas" - or how the common law might be viewed as an historical study in the way society thinks.

What Holmes adds is an addendum to Mill's "Not one iota is added to the proof by interpolating a general proposition" (1862: 232). Where Mill simply dismisses that assumption, Holmes seeks a deeper explanation of the relation of particular judgments to general propositions. Focusing on the nature and origin of the general itself, Holmes attributes its emergence to a "series of determinations on the same subject." These are not already given, as they arguably are in the classic example "all men are mortal," but represent separate judgments in varying circumstances by a community of inquirers, viz., the disparate courts of law.

The topic of interest to Mill was a simple confusion over logical form; the general proposition "all men are mortal" is but a set of unquestionably comparable particulars. But what if the particulars are not patently comparable, as in a set of novel situations or judgments? Then it is certainly not appropriate to "take the shortest cut from premises to conclusion," as Mill puts it (1862: 233). Holmes has highlighted a distinct problem, that of social classification and the emergence of consensus. If the very "general" in question is yet unestablished, a new realm of issues is opened up. Instead of how the individual thinks, it is how society thinks, how new generalized beliefs are formed despite the inevitable conflict of perceptions and views.

11 The great debate between Mill and Whewell is nearly forgotten today, even though recently analyzed in detail by Snyder (2010). It was fresh in the minds of the early Metaphysical Club, and it is a necessary resource to put the origins of pragmatism in full perspective. Recovering this perspective now is difficult, especially given the recent transformation of pragmatist philosophy by a dominant analytical attitude, flourishing (even while diverse) with W. V. O. Quine, R. Rorty, R. Brandom and others.

12 An aid to recovering the earlier perspective is Whewell's own preface to the second edition of his Philosophy of the Inductive Sciences (1840), a passage in a book that Holmes appears to have listed in the diary of his reading in 1866-7:

On the subject of this doctrine of a Fundamental Analysis, which our knowledge always involves, I will venture here to add a remark, which looks beyond the domain of the physical sciences. This doctrine is suited to throw light upon Moral and Political Philosophy, no less than upon Physical. In Morality, in Legislation, in National Polity, we have still to do with the opposition and combination of two Elements; of Facts and Ideas; of History, and an Ideal Standard of Action; of actual character and position, and of the aims which are placed above the Actual. Each of these is in conflict with the other; each modifies and moulds the other. We can never escape the control of the first; we must ever cease to strive to extend the sway of the second. In these cases, indeed, the Ideal Element assumes a new form. It includes the Idea of Duty. The opposition, the action and re-action, the harmony at

European Journal of Pragmatism and American Philosophy, V-2 | 2013 
which we must ever aim, and can never reach, are between what is and what ought to be; between the past or present Fact, and the Supreme Idea. The Idea can never be independent of the Fact, but the Fact must ever be drawn towards the Idea. - The History of Human Societies, and of each Individual, is by the moral philosopher, regarded in reference to this Antithesis; and thus both Public and Private Morality becomes an actual progress towards an Ideal Form; or ceases to be a moral reality. (1840: $x$-xi)

The passage summarizes a thesis regarding the relation of the particular to the general in the historical progress of science, Whewell's "doctrine of a Fundamental Analysis," and claims that it should "throw light upon Moral and Political Philosophy, no less than upon Physical." As such it might be seen as a call to joining the two disparate areas of inquiry that the club, and in particular Holmes, would follow.

What was Whewell's thesis? Without getting deeply into the body of his work, it is the idea of a reciprocal and research-centered growth of knowledge created by a tension between the particular and the general: the opposition, interaction, and eventual "colligation" (a form of combination or negotiation) of the two critical elements, "facts and ideas." These, he says, tend to be seen as in "conflict" with each other, but over time "modify and mould" each other. Moreover, the tension between them is itself transformative; as inquiry progresses, "the Ideal Element assumes a new form." Further, they progress toward a "harmony at which we must ever aim, and can never reach... The Idea can never be independent of the Fact, but the Fact must ever be drawn towards the Idea" (1840: xi).

The epistemic context implied by this is social, rather than strictly individual. Whewell implies a process engaging an extended community of inquirers, both physically and chronologically. Moreover, he insists that it is applicable not just to natural science but to moral and political philosophy. Given that Whewell's work was read and discussed in the semi-organized meetings of Metaphysical club members, and clearly influenced Peirce's notion of abduction and fallibilism, it may also have supported Holmes's 1870 idea of "successive approximation." The precise genealogy of a common perspective among the Cambridge intellectuals is elusive, but my purpose here is to highlight a common thread: understanding the social dimensions of knowledge, and the relation of intersubjective classification to the resolution of doubt and uncertainty.

The epistemic context of social classification is diachronic and transitional, whereas the syllogism is synchronic and analytical. For the latter, doubt is largely a failure of fit. For the former, it is a matter of provisional responsive adjustment to the arrangement of a changing order. For Mill, the reason why Lord Mansfield's hypothetical decision-maker should "never venture on assigning reasons" is his intuitive sense of similarity; but for Holmes, it is the distinctive future significance of a novel problem. The situation itself is new, a "case of first impression," having key aspects yet to be classified. The bearing of particular to general for Holmes is not one of logical relation but consensual emergence, integration from repeated experience into a dynamic and always emergent system of order. This attitude implies a distinct approach to uncertainty, as experience yet to be integrated within a moving system of classification. 


\section{Social Dimensions of Legal Uncertainty}

17 At about the period in which the Club was active, Holmes published the above-quoted essay (1870) in which he referred to the process of common law interpretation as proceeding by "successive approximation." While he did not reiterate this term, the concept behind it reappears throughout his career, woven into his conception of the judicial role in legal interpretation generally, whether strictly engaging common law, or later even aspects of statutory and constitutional law. "New cases will arise which will elude the most carefully constructed formula. The common law, proceeding, as we have pointed out, by a series of successive approximations - by a continual reconciliation of cases - is prepared for this, and simply modifies the form of its rule." (Holmes, 1870: 2).

What might here be called Holmes's "legal fallibilism" is, like Peirce's, a response to new experience: no general formulation can ever be "final." A flexible system of law requires constant retrospective reclassification of disputes. This is assumed by the common law tradition - the day-to-day and case-by-case operation of English and American courts of law. This argument requires holding in abeyance the conventional conception of law as dominated by legislation, with the main mechanism of social choice through law deriving from representative democracy at all levels. Holmes preached deference to clear legislative language, but recognized the ongoing need to fill in the "interstices."

In an ambiguous area the common law process begins with intuitive particular judgments. It is a process parallel to that of Peirce's community of scientists engaged in the exploration of a common and ongoing, but specific, problem. The "many minds" mentioned in the passage include trained judges, as well as lawyers on opposing sides of a succession of recurring disputes that, when arising at the first instance, are better resolved without prejudgment according to deduction from a preexisting principle. Hence the "business man suddenly appointed judge" should decide the case on its facts but refrain from explanation, and the same indeed goes for "more educated courts." The caution against premature generalization applies to the expert as well as to the unspecialized.

20 An early decision in an emergent controversy operates akin to a scientific experiment; it opens inquiry by creating a potential precedent for future similar cases. Like the record of scientific inquiry, that of legal inquiry consists at first of carefully recorded observation of multiple concrete experiences. The "business man" to whom Holmes alludes was acting in this instance more like a jury than a judge, and the role of juries has, since their emergence as deciders of factual questions, been to reach a decision without legal explanation from their findings on the evidence.

21 Multiple evidentiary findings can reveal similarities. After an accumulation of particular decisions discloses a pattern, according to Holmes's text, lawyers and judges initiate the process of generalizing. In law, as perhaps in science, it is only after sufficient experience establishes a clear pattern that trained observers may begin to "abstract" a "general rule." And, as roughly also in science, this is done by "reconciling the cases," which refers to the distinguishing of relevant from irrelevant detail in the articulation of a common rule or standard. Relevance, of evidence to ultimate conclusion, in both law and science, is an emergent property. As the notion of relevance emerges, so also does the perception - or imposition - of coherence. 
西

This suggests a parallel between scientists and lawyers evaluating and generalizing within an established professional tradition from records of diverse but related data. The data itself, in science and law, would appear radically distinct, but there is a sense in which the two forms of inquiry are comparable. Both are prompted by practical problems or doubts confronting the community at large, reflecting Peirce's doubt-belief model of inquiry. In both, informal and non-professional attempts to resolve such problems, once burdened by something akin to superstition, have been replaced by formal and professionalized analysis. The practical understanding underlying legal disputes has, as Holmes suggested in The Common Law (1881), supplanted a primitive culture of revenge, even as we might say that science has supplanted animism and superstition. In both, abstraction and systematic classification have been accompanied by new practices of description and conceptual objectification.

Both legal and scientific knowledge might be viewed as forms of community inquiry, focusing on the primacy of cases and exemplars in the process of intersubjective classification, and on the dual role of concepts and theories in both guiding the conduct of professional inquirers and framing and maintaining the coherence and consistency of both expert and general belief.

\section{Conflict and the Resolution of Inconsistency}

Peirce commented in 1869 that Whewell "has shown with great elaboration that in every science two processes have taken place. One, the observation and grouping of facts. The other, controversies which resulted in the establishment of clear conceptions" (W2: 340). The law is plainly driven by controversy, and Holmes elaborates on this. Legal concepts demarcating rights and duties are cognitive products of opposing as well as prevailing patterns of conduct, gathered and evaluated by courts of law. When legal rights are seen to conflict in the abstract, the conflicts are best resolved on an experimental, case-bycase basis, just as the conflicting rights were themselves individually framed.

5 If this "fallibilist" account of the emergence of legal concepts is even roughly accurate, it should illuminate the challenge of resolving conflicts among legal rights and duties. Emergent rights are rooted in individual judgments, by jurors and others like the "business man," made by comparing injurious with prudent conduct. The grounds on which such judgments are initially made is the familiarity of juries and judges with prevailing standards of conduct in the community at large, with respect to the activity engaged in when an injury has occurred. In some matters there is yet to exist a prevalent standard. The very process of particular judgment is part of the process of framing indeed of the process that Whewell refers to as "moulding."

The chronology, and diachronicity, of this process is important. Standards of conduct are preceded by, and drawn from, patterns of activity. The standards of prudence are inferred from familiarity with the better ways that things are being done, with particular concern to ground judgments upon that which is seen to be the prudent or 'correct' way. Failure to display a certain kind of light on a ship at night, which has become a common practice to decrease the likelihood of collision, becomes, through repeated common law decisions, a reason for strict liability for collisions whenever the light was absent. Thus may common practice lead by accumulation of judgments to a legal duty. 
In this admittedly simplified account, legal concepts demarcating rights and duties are cognitive products of prevailing patterns of conduct as gathered and evaluated by courts of law. This has special relevance for the methodology of resolving conflicts. When legal rights are seen to conflict in the abstract, Holmes's account denies that they can be "balanced" in the abstract. Rather, the conflicts have to be resolved on an experimental, case-by-case basis, just as the conflicting rights were themselves individually framed. Here is how Holmes described the process of conflict resolution in 1873:

The growth of the law is very apt to take place in this way: Two widely different cases suggest a general distinction, which is a clear one when stated broadly. But as new cases cluster around the opposite poles, and begin to approach each other, the distinction becomes more difficult to trace; the determinations are made one way or the other on a very slight preponderance of feeling, rather than articulate reason; and at last a mathematical line is arrived at by the contact of contrary decisions, which is so far arbitrary that it might equally well have been drawn a little further to the one side or to the other. (Holmes, 1873: 654)

In this description, as in the 1870 text, conflicts among existing rights are not resolved at once, through interpretation and application of an antecedent underlying set of legal principles. Instead they are gradually explored, first by gathering new experience, and then by appropriately timed retrospective examinations of an array of specific prior decisions. Holmes describes a process whereby the new cases are seen as gradually filling a metaphorical space between the two rules ("cluster[ing] around the opposite poles"). Judges eventually resolve the conflict by recognizing and describing a "line" between the opposing poles or principles.

Ultimately the conflict may be resolved by the reasoned analysis of an appellate court. What that means is not deduction from a priori principles but a retrospective accounting for the various dimensions revealed by successive decisions. Despite the emphasis of specific judgments, there is no attempt here to avoid the language of objectification; indeed Holmes deploys a concrete metaphor of "line drawing" to emphasize the primary role of particular decisions. Each new decision is recorded in his account as a point on a metaphorical line defining the boundary between still-evolving separate categories. This image of a "clustering" of cases prompts a comparison with scientific research as more recently described by Barry Barnes, David Bloor and John Henry (founders of the "Edinburgh school" of science studies) in Scientific Knowledge: A Sociological Analysis (1996), noting that, in science also, a "cluster of instances is all that ostensive learning can provide to convey the sense of sameness" (Barnes, Bloor \& Henry, 1996: 49).

To describe the growth of scientific knowledge as a movement from one problem to the next on the basis of analogy and direct modeling is to offer a finitist account of the process... A class is its accepted instances at a given point in time: those instances are the existing resources for deciding what else belongs in the class, the available precedents for further acts of classification, the basis for further case-tocase development of the classification. (Barnes, Bloor \& Henry, 1996: 105)

Holmes in 1873 had taken his approach a step further, in applying it to an account of the interaction between conflicting or opposing classes, by his gradual and consensual drawing of a metaphorical line. In one sense the line may be described as "arbitrary" in that it "might equally well have been drawn a little further to the one side or to the other" (1873: 654). In another sense, the account describes a process in which conceptual products are constructed not unlike physical products. There is no perfect or ideal shape to law, even as it is repeatedly modified to adapt to new conditions, shaping conduct as it forms and reforms legal concepts. 
31 From these early and other Holmes texts it appears that the body of law is built up from legal categories and concepts formed by a process akin to negotiation, albeit an attenuated one. The whole enterprise must be woven together while being adjusted to accommodate shifting standards guiding future conduct. Different cases, situations, parties, judges, and lawyers (and, of course, scholars) are all involved over a continuum, as diverse judgments are analyzed and interpreted to forge eventual settlements of multiple controversies. Overall consistency is a dominant goal, but conceptual analysis is only partly an exercise in logical reconciliation. It is also one of negotiating each new requirement for conduct through the clash of conflicting patterns of conduct already prevalent.

\section{Syllogistic Logic Socialized}

On October 24 1866, Holmes attended the first in a series of twelve Lowell Lectures by Charles S. Peirce in Boston, Massachusetts. Peirce's topic for the series was "The Logic of Science, or, Induction and Hypothesis." The first lecture, an examination of types of deductive syllogism, Peirce introduced apologetically as

an exceedingly dry subject which I cannot hope to make entertaining; but the great importance of which to everyone who is to use his mind at all ought to render it interesting... Logic is a much abused science. Like Medicine, Law, and in short any branch of knowledge which has important practical bearings, it is... no more perfect than any other product of humanity and we have the same right to be dissatisfied with its present state that we have with everything else that we are in a condition to improve. (W1: 358, Peirce's emphasis)

Holmes's daily diary, kept for just two years in the period following his return from the Civil War, reveals that he would attend only the first four of Peirce's lectures, which included diagramming and analyzing various Aristotelean and Theoprastian syllogisms, comments on Zeno, John Locke, Augustus De Morgan, William Hamilton, David Hume, James and [John] Stuart Mill, eventually (in Lecture Three) producing a bag full of colored balls and removing them one by one to demonstrate the experience of induction. His fourth lecture moved from the bag of balls to an extended critique of J. S. Mill's treatment of the syllogism in A System of Logic.

34 A comment by Peirce in Lecture Two, that may have influenced Holmes, came after a warning against abuses of the syllogistic form. "[T]o say that If the wind is east the barometer rises, is equivalent to saying Every east wind makes the barometer rise. But such a transformation will not enable us to throw arguments into syllogistic form." The example Peirce gave was:

If the wind is east the barometer rises

The wind is east

The barometer rises.

The problem, Peirce noted, is that "we talk here of occasions instead of things as in ordinary propositions; and the objects which our terms denote are bounded by dates not by positions" (W1: 379-80, Peirce's emphasis). Perhaps it occurred to Holmes, then or thereafter, that legal decisions too are occasions bounded by dates, not things by position, and that gathering them together in legal analysis or interpretation was not "an ordinary proposition." 

from the Boston Atheneaum and, amidst a severe bout with flu, slogged through its 1100 pages in a week, even while feeling "like a beast" from severe influenza. Four years later, Lecture Four appears to have born indirect legal fruit. The passage from Mill's Logic commenting on Lord Mansfield would resonate in Holmes's first essay on legal logic, gain traction in his early essays on legal theory, and lead a decade later to an emphatic concern in The Common Law with "the paradox of form and substance in the development of the law":

In form its growth is logical. The official theory is that each new decision follows syllogistically from existing precedents. But just as the clavicle in the cat only tells of the existence of some earlier creature to which a collarbone was useful, precedents survive in the law long after the use they once served is at an end and the reason for them is forgotten. The result of following them must often be failure and confusion from the merely logical point of view. (Holmes, 1881: 35)

This marks a full expression of his philosophy as it had developed by 1881. While retaining a pretense of Aristotelean deduction, law embodies an evolving system of classification, continually adapting to normative human demands as new traits are introduced and old ones shrugged off. Holmes stressed that the process of legal classification appears more analytical than it is, in the sense that consistency always seems to have been discovered, not made.

The truth is, that law hitherto has been, and it would seem by the necessity of its being is always approaching and never reaching consistency. It is for ever adopting new principles from life at one end, and it always retains old ones from history at the other which have not yet been absorbed or sloughed off. It will become entirely consistent only when it ceases to grow. (Holmes, 1881: 36)

Many years later, Holmes compared his jurisprudential theory to anthropology:

It is perfectly proper to regard and study the law simply as a great anthropological document. It is proper to resort to it to discover what ideals of society have been strong enough to reach that final form of expression, or what have been the changes in dominant ideals from century to century. It is proper to study it as an exercise in the morphology and transformation of human ideas. (Holmes, 1899: 212)

Here we find what I have called Holmes's legal fallibilism (or, in his words, "successive approximation") elucidated as a mechanism of an evolutionary theory of knowledge. I have traced its roots at least in part to Peirce's 1866 Lowell Lectures, critiquing Mill's view of the syllogism.

Peirce had begun his examination of Mill's doctrine of induction in reference to his experiment with the bag of balls, having removed seven of them at random, all appearing to be the same color. How, he asked, do we infer that the others in the bag are also red? Mill held that "it is essentially an inference from one instance to another."

Suppose, now, that we ask Mr. Mill this question which we have put to ourselves in reference to these balls. What is the Ground of Induction? His answer will be, it is the Uniformity of Nature. It is to the examination of this reply that I propose to devote the remainder of this lecture. (W1: 413)

Peirce challenged Mill's position for circularity: "to make our warrant for induction (that is his phrase) proved by induction (again his phrase) he falls into that common fallacy called "begging the question" (W1: 414). Peirce's point goes to the essence of Mill's disagreement with Whewell, where Mill deflated the role of hypothesis in the observer's understanding of individual facts. From where, then, does the sense of similarity derive? 
Mill's position requires falling back on the notion that observed uniformities are natural, rather than a result of imaginative human inquiry.

Now in opposition to this I would observe that there are obviously many more relations in nature which are totally irregular than of those which are uniform.

(W1: 417)

This observation was followed by the comment, "Every student of physics knows that a law which is exactly conformed to in nature without interference from other laws is almost if not quite unknown. Every law that is discovered therefore is found to after a few years not to be exact." (W1: 420).

Peirce's comments on Whewell a year earlier in his Harvard Lectures of 1865 are undeniably sympathetic to "colligation" between scientific facts and ideas, and suggest its influence on his later references to fallibilism and abduction. Yet, as I have suggested, Holmes's immersion in legal research led to a distinct perspective, reflecting the problem of resolution of ongoing disputes in the law. Assuming Whewell's influence on both men, colligation takes on a more pronounced social dimension with Holmes.

As noted earlier, legal judgments are not objects with extension, like colored balls in a bag; they are more like the "occasions" of Peirce's Lecture Two. And, the gradual assessment of legal disputes, and their resolution, is rarely limited to a single mind, or even a succession of single minds. Colligation involves an ongoing community of reflecting and responding agents. A single legal decision is by no means the whole story of the resolution of a legal problem. An adequate resolution of doubt must extend to the entire community of affected actors. The final "colligation," as in a complicated question like the legality of affirmative action, assisted suicide, or abortion, may take years or even generations, and (as Holmes wrote in 1870) "embodies the work of many minds, and has been tested in form as well as substance by trained critics whose practical interest it is to resist it at every step" (Holmes 1870: 1).

Pragmatic fallibilism, then, is a social phenomenon, denoting the provisional nature of knowledge as it applies to discrete problems. Whewell's use of colligation to describe the emergence of laws and concepts in science fits better with the social element of pragmatist thought than the syllogism. In Whewell's wake, law and science may be seen as branches of the sociology of knowledge. Legal and scientific knowledge can be viewed broadly as forms of community inquiry, focusing on the primacy of cases and exemplars in the process of intersubjective classification, and on the dual role of concepts and theories in both guiding the conduct of professional inquirers and framing and maintaining the coherence and consistency of both expert and general belief.

\section{BIBLIOGRAPHY}

BARNES B., BLOOR B. \& HENRY J., (1996), Scientific Knowledge: A Sociological Analysis, Chicago, Chicago University Press. 
FISCH M., (1942), “Justice Holmes, the Prediction Theory of Law, and Pragmatism," Journal of Philosophy, v. 39, no. 4.

HOLMEs O. W. Jr., (1870), “Codes, and the Arrangement of the Law," Reprinted in Kellogg (1984).

HOLMES O. W. Jr., (1873), “The Theory of Torts,” reprinted in Kellogg 1984.

HOLMES O. W. Jr., (1881), The Common Law, Boston, Little, Brown \& Co.

HOLMES O. W. Jr., (1899), "Law in Science and Science in Law," in Collected Legal Papers, New York, Harcourt, Brace and Howe, 1920.

KELLOGG F. R., (1984), The Formative Essays of Justice Holmes: The Making of an American Legal Philosophy, Westport, CT, Greenwood Press.

KELLOGG F. R., (2007), Oliver Wendell Holmes, Jr., Legal Theory, and Judicial Restraint, Cambridge, Cambridge University Press.

MILL J. S., (1862), A System of Logic, London, Parker, Son, and Bourn.

PEIRCE C. S., (W1) (1982), Writings of Charles S. Peirce: A Chronological Edition, Vol. 1, Bloomington, Indiana University Press.

PEIRCE C. S., (W2) (1984), Writings of Charles S. Peirce: A Chronological Edition, Vol. 2., Bloomington, Indiana University Press.

SNYDER L. J., (2010), Reforming Philosophy: A Victorian Debate on Science and Society, Chicago, University of Chicago Press.

WHEWELL W., (1840), The Philosophy of the Inductive Sciences, Founded Upon Their History, London, John W. Parker (2 vol.).

\section{ABSTRACTS}

Nineteenth-century references to the syllogism by J. S. Mill and Oliver Wendell Holmes Jr. reveal a distinct approach to the logic of inference in the formative years of pragmatism. In the latter may be found an element of the emergence of generals from particulars. Fallibilism in law and science reflects their social dimension as part of the communal ordering of experience. This implies a distinct approach to uncertainty, as experience yet to be integrated within a developing system of classification.

\section{AUTHOR}

\section{FREDERIC KELLOGG}

The George Washington University

frederickellogg[at]gmail.com 